\title{
MISCELLANEA
}

\section{The Prescription of Industrial Disease}

\author{
RONALD E. LANE
}

During the last few years there has been a feeling in some quarters that the provisions of the National Insurance (Industrial Injuries) Act relating to diseases caused by occupation have been unnecessarily rigid. In May, 1953 , the Minister of National Insurance set up a Committee under the chairmanship of Mr. F. W. Beney, Q.C., to " review the present provisions of the National Insurance (Industrial Injuries) Act under which benefit is paid for diseases and for personal injuries not caused by accident and to make recommendations". In August last the Committee published its report*; unfortunately, this was not unanimous and the Trade Union members of the Committee furnished a minority report.

Under the Act the Minister is empowered to prescribe by regulation certain diseases acquired in certain occupations which qualify the sufferer for a higher rate of benefit than is provided under the National Insurance Acts. It had been suggested that prescription was restrictive and unfair and that the Act should treat diseases in the same way as accidents and provide cover for all diseases that could be shown to be due to occupation. The Committee agreed that if it were practicable such cover would be the proper one, but after hearing much evidence it decided that such a scheme was not workable. Whereas the proof that an accident occurred at work was comparatively easy, the attribution of many diseases to occupation was difficult and often impossible. Many of the questions that arose were unanswerable in the present state of medical knowledge.

"A man working out of doors might claim that ordinary climatic conditions were a cause of his arthritis. A clerk might allege that the sedentary nature of his work over many years was responsible for his chronic indigestion or even his coronary thrombosis. A manager or someone else whose work involved mental stress might claim that this was the cause of his peptic ulcer or perhaps of his neurosis."

It was regarded as futile to expect individual doctors to answer questions that the medical profession as a whole could not answer. Inevitably different decisions might be given on cases presenting similar facts. Medical certificates would tend to fall into disrepute and a litigious atmosphere might develop, with protracted disputes which would have an adverse effect on health. A great number of claims would probably be rejected, with

- Report of the Departmental Committee Appointed to Review the Diseases Provisions of the National Insurance (Industrial Injuries) Act. resulting disappointment and dissatisfaction. When it is remembered that bronchitis and rheumatism alone account for well over a million spells of sickness each year it will be realized how widespread this dissatisfaction might become.

For these reasons the Committee concluded that general cover was not practicable and turned to examine another suggestion, namely that of providing cover for those who work in certain unfavourable environments and develop a common disease which might be related to those working conditions, for instance sufferers from chronic bronchitis whose work exposed them to abrupt changes of temperature. Such a scheme, however, would give all patients on this type of work who suffered from chronic bronchitis an irrebuttable presumption that their disease was caused by their work. This would obviously be unjust to the fund and would in fact be opposed to the industrial injuries scheme which requires that the individual case is capable of proof. The Committee therefore rejected this suggestion and decided that the system of prescription should remain.

The Committee then considered the present working of the Act and reviewed the requirements for prescription. The conditions which must be satisfied before a disease can be prescribed are contained in the famous Section 55 of the Act. Subsection (2a) of this Section deals with the scientific information about the disease establishing its relation to occupation, while Subsection (2b) deals with the feasibility of proving causation in the individual case. The principle defined in Subsection 55 (2b) caused the Committee much difficulty. The Samuel test in the old Workmen's Compensation Act required this proof uncompromisingly; the present Act requires it, but less rigidly; as defined by the Dale Committee this condition is satisfied if proof is of the same standard as required in civil law cases, e.g., " more likely than not". For instance, this condition has been regarded as satisfied where an exceptionally high incidence of a disease occurs in a given occupation-such as cancer of the bladder in chemical workers. It has also been regarded as being satisfied in tuberculosis among health workers, though here the excess incidence is much less. The Committee points out, however, that in general " arithmetical tests" are unsatisfactory for this purpose since it can never be known whether the particular claimant under consideration is one of the "excess" or would have been found among the "normal incidence".

The minority report seizes on this argument and points out that in both these instances it is rarely, if ever, possible to be certain whether any individual case is of occupational origin. Accepting the prescription of these two diseases as sound (as does the whole committee) the minority report goes on to urge that incidence rather 
than the attribution of individual cases must be the method which determines prescription in the future. The T.U.C. members press that a disease should be prescribed if its occupational origin can be presumed to be more probable than not: that " most cases in the field covered are occupational " and that individual attribution should be disregarded. It would seem here that the majority and minority are not far apart. The question would appear to be what measure of excess incidence (after adequate statistical determination) is to be regarded as adequate for prescription, and for assuming 55 (2b) to be satisfied. The majority report speaks of " an exceptionally high incidence", the minority speaks of " most cases". It would seem that this is a practical point which can be settled by the Minister in each submission for prescription.

This is, however, an over-simplification, for there is a fundamental difference between the two reports. The majority is prepared to accept a high incidence of a common disease when it occurs in a well defined occupational group as satisfying $55(2 \mathrm{~b})$, but it flatly refuses to accept the view of the minority who would carry this principle much further and would seek to apply it without clear definition of the occupation and for common disease, for instance, chronic bronchitis in those exposed to dust. If this principle were pressed prescription would disappear and it would be open for any patient to prove if he could that his disease arose from his occupation, with the obvious difficulties associated with "general cover". Nor would this be all, for the problem of aggravation would loom up and doctors would be asked to guess whether and to what extent certain conditions of work had aggravated a pre-existing constitutional disease.

One gets the impression from reading the report that if some way could have been discovered of dealing with chronic bronchitis and rheumatism the minority's demand for more general cover might have been dropped. The minority report says that failure to provide cover for these two diseases is a great weakness in the existing system. Recognizing the difficulties, however, it suggests as a start that special provision should be made for older workers who have spent the greater part of their working lives in a job carrying special risk of these diseases. It is pointed out that cover could be limited by the degree of disability and duration of exposure which could be determined by special medical boards. It is interesting to recall that this was until recently the scheme for dealing with byssinosis and that it worked satisfactorily for some 14 years. There was, however, this great difference, the occupation was clearly and precisely defined. The majority report rejects this as a feasible method of dealing with the general problem since at present there is no way for a doctor to differentiate occupational from non-occupational cases.

The Committee emphasizes that if extra benefit is to be given on uncertain evidence, the present industrial injuries scheme would break down. Such a practice would have the effect of transferring many cases from the National Insurance Scheme to the Industrial Injuries Scheme and the final outcome of this might well be a merging of the two schemes. Since these are both welfare payments it might well be asked why this separation should be retained. The needs of a man who breaks his leg differ in no way whether the accident occurs at home or at work. It is true that at present he pays a little more for extra cover but there would seem no insuperable difficulty in dropping this and merging the two schemes. If there is to be a demand to extend cover to disease which cannot be proved to be industrial such a change would appear to be the only solution.

If in fact the two schemes are to be kept separate some means must be found to identify those cases of common disease which result from occupational exposure. The Committee recognized that such cases existed but differed in their method of handling the problem. The majority infer that this is a very small group and that by attempting to pay them the larger benefit to which they would be entitled under the Industrial Injuries Scheme more harm than good would be done. The minority on the other hand would prefer the few to get their " rights" at the expense of considerable injustice to the Scheme.

The Committee evidently struggled hard to find some way of covering the group of cases which were at present missing benefit. For instance, the possibility of " open prescription" was considered. This is the name the Committee gave to prescription without presumption. At present the only disease in this category is dermatitis where entitlement to benefit has to be shown even though a skin lesion is present. The Committee decided that at present no other disease was known to which this type of prescription could be applied with advantage. Such a device would, in fact, produce the same situation they were at pains to avoid, namely, the settlement of claims not on fact but on the unverifiable opinion of individual doctors.

It is not surprising, therefore, that in this impasse both majority and minority call for more knowledge-for further research in this field-and the committee is unanimous in making recommendations as to how this should be done. It is not suggested that the Ministry of Pensions and National Insurance should set up its own research organization but that the Industrial Injuries Advisory Council should keep under review the list of prescribed diseases and assume the responsibility for initiating research into current problems of prescription. In order to assist it in its work the Committee recommended the formation of a small highly qualified specialist staff and suggest that those members of the Council " concerned with industrial diseases" should keep in close touch with this staff and "provide the necessary supervision". The importance of field studies and statistical techniques is emphasized.

The report makes no mention of the very considerable practical difficulties there would be in carrying out such a scheme. It would be difficult, for instance, to attract really good research staff to work which was limited to the "problems of prescription": these are but one aspect of the much larger problem of industrial disease, a subject which hitherto has not been effectively tackled for lack of a complete organization for the purpose, and this in no way reflects on the excellent work of the Medical Research Council in this field. Other Government 
departments as well as employers and employees have a direct interest in this work and all should be prepared to join forces and resources in setting up an organization which would link factory floor with research laboratories for it is here that the greatest need lies. In this way not only could the problems of prescription be studied but many of them could be made to disappear.

\section{Conclusion}

After considering this thorny subject for two years the Committee decided to leave matters alone. While aware of the defects of the present scheme they were unable to suggest anything better. They recognized that the real problem of the future was to identify, with a satisfactory degree of precision, those cases of industrial disease which present as common illnesses.

There is no simple answer to this difficult problem but much could be done towards solving it if it could be tackled by well-trained and efficient teams but unfor- tunately these are not available at present. Medicine has neglected this field to which it has devoted too few of its resources both of brains and money. The Beney Committee has rightly called attention to this gap in medical knowledge. It is essential that small occupational groups with risks of contracting common diseases because of special hazards should be identified and separated from the large group of patients presenting identical symptoms. This work is important, not only for the administration of the Industrial Injuries Act but for the purpose of prevention. Indeed, if it were not for the preventive aspect the simplest way of dealing with the administrative problem would be to give the same benefit to occupational and non-occupational cases. Many of the arguments against this simple solution are rooted in the past and should no longer determine policy. Perhaps some future committee set up to consider the working of this Act will be specifically charged to examine the possiblity of this major change. 